\title{
Supporting Teaching and Learning Reform in College Mathematics: Finding Value in Communities of Practice
}

\author{
Kelly Gomez Johnson ${ }^{1}$ (D) Paula Jakopovic ${ }^{1} \cdot$ Christine von Renesse $^{2}$
}

Accepted: 13 September 2021 /Published online: 19 October 2021

(c) The Author(s), under exclusive licence to Springer Nature Switzerland AG 2021

\begin{abstract}
Improving college STEM (science, technology, engineering, mathematics) student learning outcomes is an ongoing area of focus in Institutions of Higher Education (IHE). This reform includes challenging, changing, and adapting both teaching practices and the learning environment. Communities of practice (CoPs) can support faculty in making these shifts; however, creating large-scale instructional changes in STEM education requires a more careful look at the existing systems and structures in place. In this paper, we investigate a network of regional CoPs composed mainly of mathematics faculty from IHE focused on teaching with inquiry methods. Understanding what faculty need and value to support their instructional changes is important as CoPs and other mechanisms are put in place to increase student success. In this qualitative study, we use the value framework developed by Wenger et al. (2011) to dissect the variety of ways faculty engage and find value in their CoP participation. Faculty participants expressed that CoP participation created unique layers of value in helping them to identify resources to support teaching with inquiry especially during a pandemic, shift their beliefs about teaching, and engage with a network of peers about mathematics and teaching. Findings from this study, conducted during the COVID-19 global pandemic, provide preliminary insights for STEM stakeholders interested in large-scale, ongoing instructional reform to improve student learning outcomes and for networks interested in collectively supporting CoPs with ongoing rather than finite goals.
\end{abstract}

Keywords Mathematics $\cdot$ Inquiry $\cdot$ Communities of practice $\cdot$ Value $\cdot$ Network

Kelly Gomez Johnson

kgomezjohnson@unomaha.edu

Paula Jakopovic

paulajakopovic@unomaha.edu

Christine von Renesse

cvonrenesse@westfield.ma.edu

1 Teacher Education, University of Nebraska at Omaha, 6005 University Drive N, Omaha, NE 68182, USA

2 Mathematics, Westfield State University, 577 Western Ave, Westfield, MA 01086, USA 


\section{Introduction}

College mathematics courses have been viewed as "gatekeeper courses" and have inadvertently lead students away from STEM (science, technology, engineering, mathematics) majors or even continuing their postsecondary programs altogether (Fayer et al., 2017; Rose \& Betts, 2001). STEM instructor effectiveness, particularly the use of evidence-based teaching methods (e.g., active learning, inquiry), has been shown to increase the knowledge, skills, and habits of students (Freeman et al., 2014; Laursen et al., 2014; Theobald et al., 2020). For the purpose of this paper, we will refer to "teaching with inquiry" as a specific subcategory of evidencebased mathematics teaching that includes methods of inquiry and active learning strategies. For mathematics faculty at Institutions of Higher Education (IHE), lack of training on teaching with inquiry methods and isolation within their departments can make instructional changes challenging (Banta, 2003). Further, without ongoing support and resources, faculty can often fall back into traditional lecture-style teaching methods, which continues to be the most predominant method of mathematics instruction in IHE (Jaworski \& Gellert, 2011; Laursen et al., 2019; Nolan, 2006, 2010). Teaching mathematics with inquiry can cause uneasiness on the part of both instructors and students when teaching and learning might look vastly different from their prior conceptions of or experiences in STEM coursework. Additionally, when STEM faculty find themselves enacting instructional change in isolation, without the support of colleagues or leadership, these changes are often not sustained over time (Lueddeke, 1999; Malcom \& Feder, 2016). Building upon previous research on faculty learning communities (e.g., Furco \& Moely, 2012), groups of STEM faculty have begun gathering to address isolation and instructional innovation with the ultimate goal of increasing student success in STEM.

Over the past 2 years, mathematics faculty from across the USA have formed grassroots, regional communities of practice referred to as COMMITs (COMmunities for Mathematics Inquiry in Teaching). A community of practice (CoP) is a group of people who share a common concern or a passion and regularly learn together to improve in their work in the particular area (Lave \& Wenger, 1991; Wenger-Trayner \& Wenger-Trayner, 2015). CoPs are more than collaborative groups. Henri and Pudelko (2003) expanded upon Lave and Wenger's (1991) conception of CoPs by creating a typology of communities to exhibit the strength of bond and intentionality. Unlike "communities of interest," "goal oriented communities," and "a learner's community," CoPs, such as the COMMITs within this study, are organized around professionals who collaborate on similar activities with high levels of social bond, involvement, mutual help and support, sharing of meaning, and identity construction (Henri \& Pudelko, 2003). While the other forms of communities may have some aspects of the aforementioned factors, CoPs in the context of STEM higher education have been shown to support innovation and change as a means to share knowledge, ideas, and resources (Austin, 2011; Kezar \& Gehrke, 2015). The National Science Foundation, for example, has funded several STEM reform efforts in recent years that investigate the use of CoPs for both faculty and students (e.g., BernsteinSierra \& Kezar, 2017; Lord et al., 2017; Tomkin et al., 2019). 
Despite research that suggests STEM CoPs can support changes in teaching practice (e.g., Kezar \& Gehrke, 2015), long-term sustainability remains a challenge especially since CoPs are often not housed within a formal organization. Kezar and Gehrke (2017) identify a gap in the literature on the sustainability of CoPs stating, "To be sustainable, they [STEM CoPs] had to move from being a loose entity typical of networks and CoPs toward being more like an informal organization" (p. 345). The loose configuration of isolated CoPs, also noted as a strength at times, can make scaling reform efforts at a national level challenging (Keza et al., 2018). To create large-scale transformation in mathematics education, which have long-standing traditions of teaching and learning practices, systems and structures must be in place to move toward systemic reform.

Therefore, unique to this study's context is the structure of the CoPs, namely, COMMITs, nested within a larger network. The COMMIT Network keeps the collection of grassroots CoPs focused on a common goal and moving in the same direction. Engel and van Zee (2004) summarize elements necessary to a successful network to include a shared goal, common interest, added value and commitment, capacity to access and contribute to the network, and clarity of planning and management. Part of the vision of the COMMIT Network is to keep mathematics faculty connected with ongoing support as the vision and needs of the CoPs evolve over time.

In this paper, we examine how COMMITs within a broader network support participating faculty members to adopt, sustain, and promote teaching with inquiry, in their own practice and within the broader IHE STEM community. This study seeks to add to the literature on identifying not only what faculty find valuable from CoP engagement, but also the types of support mechanisms and potential interpersonal connections needed to facilitate the development, growth, and sustainability of a network of non-organizationally located, COMMITs. During immense uncertainty and change in reaction to the global COVID-19 pandemic, we investigate where faculty within these COMMITs may have found value in their engagement. Understanding how to support faculty and determining what matters in their development and networking are pivotal to future planning and resource allocation to continue working toward the common vision of transforming teaching and improving student outcomes. "Value" is a complex, social construct and therefore, we use the value framework developed by Wenger et al., $(2011,2014)$ to dissect the variety of ways faculty engage in their COMMIT. The types of value we examine from the framework include immediate (in the moment resources, information, connections), potential (for the future), applied (tested implementation), realized (actualized implementation), and transformative (broader dissemination to others). We consider how implications of this investigation might inform other networks of STEM stakeholders interested in large-scale instructional reform to improve student learning outcomes.

\section{Context and Background}

It is well-established that active learning and instructor effectiveness have a positive impact on students' learning, attitudes, and experiences (De Vlieger et al., 2016; Freeman et al., 2014; Laursen et al, 2019). Research on active learning in 
STEM has shown increases in students' academic success, overall attitude toward content, and higher retention rates (Bowen, 2000) especially for students from historically underrepresented groups in STEM (e.g., people of color, women) (Freeman et al., 2014; Haak et al., 2011; Hrabowski \& Henderson, 2017; Laursen et al., 2014; Theobald et al., 2020). With a focus on inquiry and equity, active learning environments establish students as partners in the learning process with the faculty/teachers rather than passive observers (Cook-Sather et al., 2016; Healey et al., 2014, 2016; Werder \& Otis, 2010). Although previous exposure to active learning, perceptions of job security, and classroom context (e.g., class size) are factors that impact faculty implementation, instructors in all situations are able to implement active learning into their college STEM courses (Apkarian et al., 2021). These findings call for ongoing professional development and research on what supports or inhibits faculty to implement and sustain active learning strategies in their classrooms.

Although many mathematics departments in IHE recognize the research around incorporating active learning in undergraduate courses, this awareness does not always translate to successful implementation. A recent national survey found that, although $91 \%$ of IHE mathematics departments reported believing active learning to be "very important" or "somewhat important," only 15\% reported successful implementation of active learning in their program (Rasmussen et al., 2019). To help professors shift their teaching methods from more traditionally used lecturestyle instruction (e.g., Jaworski \& Gellert, 2011), the Academy of Inquiry-based Learning previously offered national week-long inquiry-based learning workshops (http://www.inquirybasedlearning.org/). While these workshops have been a great resource to several hundreds of faculty members, they have not yet provided a sustainable model to support and offer professional development for all faculty interested in teaching with inquiry. The COMMIT Network (www.COMathInquiry.org) is addressing this need by supporting regional CoPs with a space for grassroots leadership to discuss how they are supporting faculty to create more equitable and active learning environments at their regional and institutional levels.

The COMMIT Network grew rapidly from four to ten regional COMMITs with over 500 engaged faculty within the first 2 years. While each COMMIT is organizing themselves independently, the COMMIT Network provides a connection among the regional communities to learn with each other about how to best support faculty. The COMMIT Network embraces many forms of teaching with inquiry (our terminology), including but not limited to active learning strategies, inquiry-based learning (IBL), project-based learning, problem-based learning, student-centered teaching, ambitious teaching, discovery learning, team-based learning, and inquiryoriented learning. The Four Pillars (Laursen \& Rasmussen, 2019, p. 138) of inquirybased mathematics education summarize the features most important to the COMMIT Network:

- Students engage deeply with coherent and meaningful mathematical tasks.

- Students collaboratively process mathematical ideas.

- Instructors inquire into student thinking.

- Instructors foster equity in their design and facilitation choices. 
Armed with structures aligned with the Four Pillars, the COMMIT Network aims to provide structures and support to regional COMMITs to engage faculty in embedded and ongoing exposure to teaching with inquiry. This includes attention to modeling equitable and accessible professional development practices at informal and formal events, recognizing and supporting faculty of various identities, contexts, and from different institution types. Understanding how and what types of support structures individual COMMIT participants find valuable can inform a needed addition to the literature regarding the long-term sustainability of STEM CoPs.

\section{Theoretical Framework}

This study is theoretically framed on community-based approaches to change (Daly, 2010; Kezar, 2013; Valente, 1995). Due to the ongoing and complex work of higher education faculty development and networking, we use situated learning theory (Lave \& Wenger, 1991; Wenger, 1998) as the theoretical perspective of this study. Rather than focusing solely on the traditional conception of teacher/pupil learning, situated learning theory posits learning as something that occurs as individuals engage in CoPs and social networks (Lave \& Wenger, 1991).

CoPs involve many complex layers and cycles of interaction that can make it challenging to parse reasons for the success or failure of these communities. To better understand the types of structures and supports that a larger network of CoPs can provide to keep stakeholders engaged, we utilize the value framework developed by Wenger et al. (2011), to examine the intricate experiences of COMMIT participants within the larger COMMIT Network. This framework positions CoPs within "a dynamic process in which producing and applying knowledge are tightly intertwined and often indistinguishable" (Wenger et al., 2011, p. 21). Therefore, unpacking these experiences requires a systematic approach to interrogating the construct of value. The framework includes five cycles, or layers, of value creation-which include immediate, potential, applied, realized, and transformative value. One cycle does not necessarily lead to the next and the importance of the various cycles can differ for different stakeholders.

There is growing interest in understanding not only the opportunities and challenges of measuring "value" as a construct of CoPs, but also examining the variety of contexts and layers of value that exist within these settings (Guldberg et al., 2021; Smith et al., 2017). For example, Boothe and Kellogg (2015) utilized the value framework specifically to examine value cycles within online communities of practice. They identified labels for each type of value consistent with this study's codebook definitions: immediate value-productive activities, potential value-knowledge capital, applied value-promising practices, and realized value-"return on investment" (i.e., seeing the payoff/benefit of the new knowledge implementation in practice). Clarke et al. (2021) utilized the value framework to develop "ground narratives" that allowed them to identify themes within the broader community.

Thus, this value framework is designed to interrogate various types and sources of data to develop a compelling picture of how a COMMIT provides value to participants. As such, it is well situated to examine the experiences of COMMIT Network 
participants in regional activities and events over time. This study seeks to answer the question, "What do participants in regional COMMITs within a larger network find valuable?" to better understand the role a larger CoP network can play in helping to create sustainable communities over time.

\section{Methodology}

The COMMIT Network is currently funded by a National Science Foundation grant (No. \#1,925,188). The authors of this study include two researchers who are members of the grant leadership team tasked with gathering and analyzing data about the network to make programmatic improvements and report findings to the broader mathematics education community. The third author is a member of the grant leadership team and also a regional COMMIT leader. A goal of the grant is to understand how the COMMIT Network engages participants in activities, and whether this engagement is meaningful in supporting faculty who wish to know more about and/or implement teaching with inquiry practices in their mathematics courses.

\section{Participants and Setting}

At the time of data collection for this study, there were a total of five COMMITs engaged within the network. The participants from this study include faculty from a broad range of institution types. Coverage of survey responses represent faculty from K-12 schools (4\%), 2-year colleges (10\%), doctoral granting institutions (18\%), and predominantly undergraduate institutions (68\%). The participant sample includes individuals who participated in events facilitated by COMMITs within the broader COMMIT Network. Data collection for this study took place across the first year of the grant, from October 2019 to October 2020, and participants completed a total of 227 individual surveys. After attending any COMMIT activity, we invited participants to complete a brief, voluntary survey aimed at identifying the types of value they found engaging in the event (Appendix A). Within the survey, participants identified one or more COMMIT activities from a list or added their own. To protect participant anonymity, they were not obligated to provide personal or demographic information, including their name or institution. Of the 227 responses, 115 unique faculty participants provided identifiable information for a total of 156 sur-

vey responses. Some of those 115 participants filled out the survey more than one time, but no single identified participant filled out the survey more than five times across the 1-year period.

\section{Data Collection and Analysis}

We utilized an online survey to gather data about participant experiences in regional COMMIT activities. The survey incorporated a combination of multiple choice and open-ended follow-up prompts to help participants identify what value (if any) they found engaging in activities and to what extent participants planned to implement 
ideas learned from these activities in their practice. We were particularly interested in the open-ended prompts, as this qualitative data allowed us to examine "how people interpret... and attribute meaning to their experiences" (Merriam, 2009, p. 5). Authors 1 and 2 began coding the data together to calibrate codes, using a mix of deductive and inductive coding. Coding the data simultaneously helped to ensure intercoder reliability by building consensus (Bradley et al., 2007; Krippendorff, 2004). We began data analysis by identifying instances where participants reported finding value engaging in COMMIT activities. When participants responded "Yes" to items 5, 6, and 7 on the survey (see Appendix A), we identified these as responses that indicated participants found value in the activity. We adapted the value framework developed by Wenger et al., $(2011,2014)$ to deductively code follow-up openended responses for evidence of value across five value types: immediate, potential, applied, realized, and transformative. Item 5 on the survey asked respondents whether they learned anything new by participating in activities, which we coded as "Immediate Value," as they found new information useful in the moment. Item 6 asked whether respondents planned to implement ideas learned from COMMIT activities into their future practice, and we coded these instances as "Potential Value," indicating that participants saw possibilities in the future where the new learning could be valuable. Item 7 asked participants whether they planned to share anything they learned with a colleague. We coded these instances as "Transformational Value," as they relate to dissemination of the new ideas to a broader audience. We then examined the follow-up open-ended response for each of these coded items to identify potential themes across the data. Table 1 breaks down how many of the total 227 surveys returned had respondents who identified finding immediate, potential, or transformative value in the COMMIT event they attended. Not all participants completed the subsequent open-ended prompt. The table also indicates, of the affirmative responses, how many respondents included a follow-up, qualitative response that the research team coded.

In the second round of coding, we utilized a priori codes where we identified responses that aligned with one of the Four Pillars (Laursen \& Rasmussen, 2019). We determined that these four codes did not completely capture the essence of all participant responses; therefore, we conducted a third round of descriptive coding (Miles et al., 2014; Saldaña, 2015) where we identified additional emergent codes in the data. These codes included resource sharing, ideas for technology integration, forms of assessment, evolving beliefs about teaching mathematics, and the usefulness of their regional COMMIT. At times, participant responses included integrated

Table 1 Coding round one: number of survey responses coded for value

\begin{tabular}{ll}
$\begin{array}{l}\text { Total number of surveys where } \\
\text { respondents completed open-ended } \\
\text { prompts }\end{array}$ & $\begin{array}{l}\text { Total number of coded, qualita- } \\
\text { tive responses from open-ended } \\
\text { prompts }\end{array}$ \\
\hline 196 & 170 \\
217 & 181 \\
219 & 132 \\
\hline
\end{tabular}




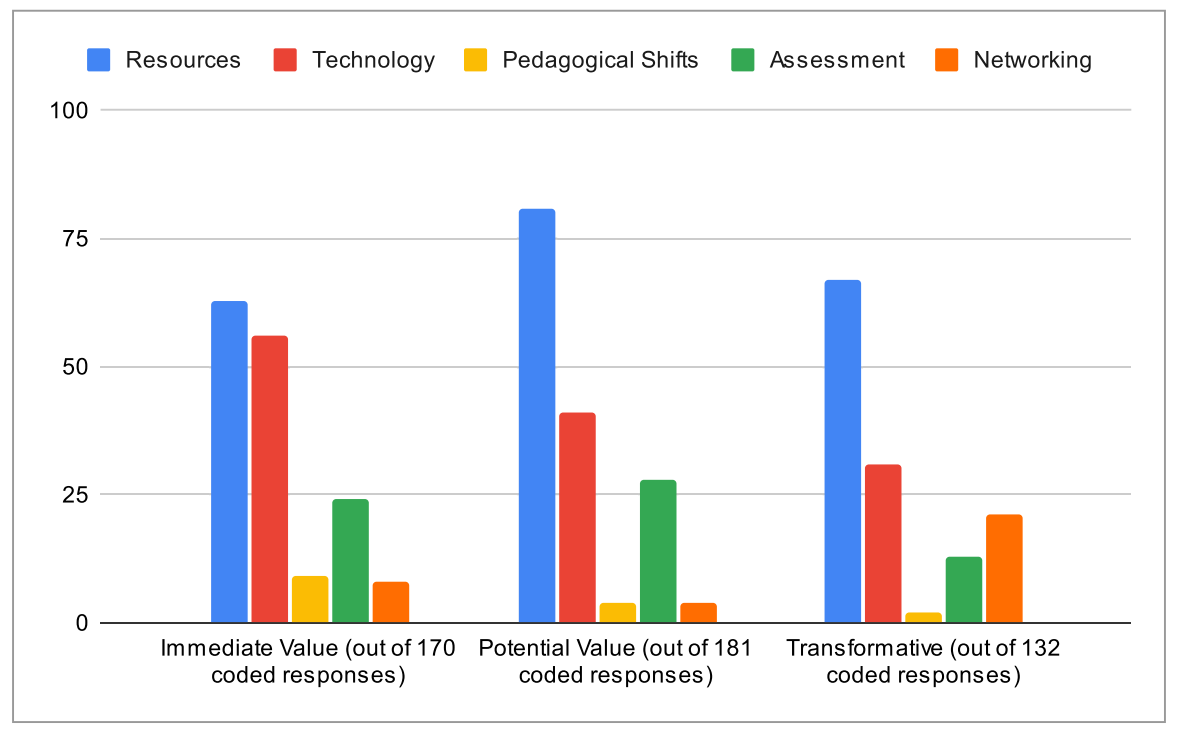

Fig. 1 Coding round three: participant-reported value

elements of multiple codes; therefore, we dual coded responses tied to more than one code. Figure 1 identifies the saturation of these codes broken down by value type across the coded survey item responses.

Finally, we reread and refined codes in order to synthesize our findings and develop emerging themes, which we describe in the next section.

\section{Results}

In this study, we aimed to identify what participants found most valuable from their engagement in their COMMITs focused on teaching with inquiry. Embedded within the value framework, we examined what participants found to be valuable in a variety of ways (Wenger et al., 2011, 2014). Furthermore, we identified aspects of engagement that participants identified as valuable enough to consider implementing in the future or sharing with others, within or outside of their COMMIT. We identified three major themes across the data based on the interconnected nature of what participants reported valuable: (1) support with resources to improve practice, (2) support through belief shifts in theory and practice, and (3) support of a community of peers.

\section{Support with Resources to Improve Practice}

We hypothesized that many respondents would identify resources as a new idea (immediate value) learned by engaging in a workshop or COMMIT activity. Indeed, 
a number of participants identified a resource (tool, strategy, website, repository, etc.) as a new strategy or idea. Participants who engage in COMMITs represent diverse exposure to and experiences with teaching with inquiry. Participants reported nearly equal familiarity, or lack thereof, about teaching with inquiry and the existence of their CoP ranging from very familiar to not familiar at all on a 4-point scale. Those who were less familiar typically identified "IBL basics" or concepts that are directly related to the pillars of active learning (Laursen et al., 2019) as their primary takeaway from participation. In total, of the 227 responses, 27 responses to item 5, 17 responses to item 6, and 10 responses to item 7 were coded as "IBL Basics." Participant comments such as "I learned what IBL is!", "I didn't know what IBL was before the workshop!", and "Lots of tips and ideas for setting up my first IBL classroom" revealed that newcomers to COMMITs were provided with foundational information and resources to take the initial steps toward teaching with inquiry.

An unanticipated finding, but perhaps obvious in the context of COVID-19 conditions, was that when we dual coded resources with technology integration, all instances occurred on or after March 28, 2020 (the start of the COVID-19 outbreak in the USA and related university shutdowns). Many faculty members had to pivot toward online only methods of instruction, with or without teaching with inquiry components. Through the network, participants were able to continue their engagement in virtual "classroom visits" (58 responses) and workshops (153 responses) allowing them to see instruction in their peers' spaces. One participant shared, "I learned a lot about implementing IBL online. I didn't think it was possible, but now I know it is."

Survey respondents identified assessment resources as another valuable aspect of their COMMIT event participation. Assessment conversations and resources shifted dramatically to include technology integration and online teaching strategies to better understand student learning as COVID-19 shutdowns impacted courses. Respondents highlighted a variety of formative assessment practices and tools that had potential value in their courses including "low-pressure feedback" tactics using technology. For example, participants shared technology resources like Zoom polls and other group engagement platforms to elicit evidence of student thinking with small group breakout sessions (e.g., Google Jamboard, OneNote, Voice Thread). Access to new technology tools provided participants with innovative options to both formally and informally assess student learning.

\section{Support Through Belief Shifts in Theory and Practice}

Some faculty participants may be the only instructors who teach a specific course at their institution or have other factors that isolate them from collaboration with peers outside of their CoP. Throughout the data, participants expressed value from conversations and activities that challenged traditional, long held beliefs and cultural expectations of what it means to teach mathematics. Participants highlighted new ideas and perspectives they gathered from participation that confronted traditional beliefs including sharing resources vs. being an island of 
excellence ("I hadn't realized I could just ask someone for IBL course materials"), rewiring their thinking about student participation and feedback ("A point of view adjustment...catching students doing something right, which is the opposite of what most of us math teachers do"), and the importance of designing a productive teaching with inquiry environment ("To stay out of the students' way but guide when necessary.", " ... about making the environment conducive to feeling ok to take risks and make mistakes"). Participants' recognition of the philosophical differences being discussed through many of the workshops and discussions spanned value types from immediate to transformative.

Assessment is a critical component of the teaching and learning process but is often misunderstood as solely referring to tests. Like the shifts in how participants thought about teaching mathematics, participants also identified value in considering and learning about new ways to assess student learning (e.g., "Specification based grading," "mastery grading"). According to Campbell et al. (2020),

In mastery grading, student work is graded directly on whether it meets a clear list of outcomes. Rather than awarding points or partial credit, clear expectations are set in advance for how student work will be assessed, and the instructor evaluates whether or not these expectations have been met. However, mastery grading also recognizes that these expectations set a high bar, and that learning takes time and often many mistakes. To support this, students are given multiple opportunities to demonstrate mastery of these outcomes before the end of the course.

One participant shared how the COMMIT activities extended their initial introduction to mastery grading methods from a previous summer national workshop,

I've adjusted my assessments and grading practices and increased my presemester outreach to students based on suggestions brought up in lunchtime discussions. I will be implementing mastery based grading in 2 of my sections for the fall, motivated by discussions in the IBL (COMMIT) group.

For this participant, initial interest and value in a new form of assessment was supported and applied in practice with support from COMMIT peers and activities.

The establishment of a positive learning environment where learners are positioned as active participants is a key aspect of teaching and learning with inquiry (Cook-Sather et al., 2016; Healey et al., 2014, 2016; Werder \& Otis, 2010). Along with their own shifts in thinking about teaching and assessment, participants also frequently highlighted their learning around how to build classroom community, engage students in ice breakers, and promote a more welcoming environment in their classrooms to help students "buy-in" to change. These types of activities were noted as valuable by participants because many students are also not accustomed to teaching with inquiry structures especially in college coursework. Several participants shared how valuable it was to learn about how the instructor/student relationship might be very different from the past. After participating in a COMMIT-led book study, one participant stated, 
The book we've been discussing talks about developing relationships with our students. Through reading the book and our discussions, I've gained insight into the importance of relationships, how to develop them, how to deal with difficult classes, how to recognize how our own past experiences influence relationships with students, etc.

Along these same lines, another participant shared that they learned through participating in different teaching with inquiry demonstrations how the instructor could see these experiences through a student lens (Laursen \& Rasmussen, 2019), "The activity itself was not novel, but discussing the activity as a student was the real value. I don't have much opportunity to discuss higher mathematics with others." While the statements above indicate potential value for participants to integrate teaching with inquiry practices in the future, other participants used the professional connections to make just-in-time adjustments where they were able to experience actualized value. For example, one participant described their CoP connections as having helped them make adjustments to "increase my pre-semester outreach to students based on suggestions brought up in my lunch-time discussions."

\section{Support of a Community of Peers}

A number of participants alluded to the importance of the COMMIT Network in helping them to learn from their peers across the regions and broader network. Faculty participants noted that workshops and COMMIT activities were safe, welcoming places to be vulnerable, grow, and gain confidence.

It was great meeting new people, and both getting new ideas and being able to share my ideas and feeling like an expert. The low key sharing and socializing really helped build a sense of community, which is especially valuable right now when everyone is isolated and everything is online.

This group is welcoming and inclusive. The members are passionate about IBL, generous with ideas, and open about the ways in which they struggle.

I really like how the IBL group works to learn together and is inclusive of all no matter what level of understanding and implementation of IBL they're at. This really came out through participation with the book group how everyone is willing to learn from each other.

The topology working group has been amazing. It's a great professional development model -- come together to learn some math, take turns being the leader, and reflect on pedagogy/technology. Really fun, good connections, lots of learning.

Participants highlight inclusivity throughout the data as not only a key feature of their engagement with the COMMITs, but also of teaching with inquiry environments in general. A number of participants noted the value of experiencing features of teaching with inquiry themselves. Overall, participant statements highlight the value they found in immersive activities, like live classroom observations, where they could observe strategies and later ask questions in a safe, inclusive environment (Henri \& Pudelko, 2003). 
While a network of "like-minded peers" was valued by participants and well represented in data prior to the COVID-19 shutdown, the conditions created by the shutdown intensified the desire for support. With everyone moving to online platforms beginning in March 2020, new COVID-19 conditions removed many potential barriers with attendance associated with travel (e.g., cost) and distance. COMMITs quickly organized "lunch conversations" and support groups to bring together faculty members grappling with how to teach mathematics online in general, but also with inquiry. Participants revealed relief in hearing others go through similar struggles with teaching online with comments like "it's a shared experience and a shared concern with other dedicated people." Another participant added, "This was so helpful to learn about strategies for implementing IBL online. I felt like in the winter I was teaching in a vacuum. I knew how I was teaching remotely but couldn't see what other people were doing." COMMITs once again offered access to learn vicariously with and from others and also provide support during extraordinary times of change and uncertainty.

\section{Discussion and Conclusion}

Instructional quality and teaching practices are important factors in student success and equity, especially in STEM areas like mathematics (De Vlieger et al., 2016). Improving the learning outcomes and experiences of college mathematics teaching is a complex task. Even when mathematics faculty identify the importance of using research-based practices, such as teaching with inquiry, systemic implementation of such practices can be challenging (Rasmussen et al., 2019). COMMITs offer an opportunity for faculty to meet their professional development needs with likeminded peers often outside of their institutions (Furco \& Moely, 2012). Additionally, networks that connect CoPs may add extra layers of structure and resources (e.g., network leadership meetings, network workshop facilitator meetings) to help faculty implement and sustain changes to their teaching practice. To best support the efforts of IHE mathematics departments and CoPs, we must first understand what mathematics faculty need as practitioners of teaching with inquiry. We must also examine what CoPs need to reach all faculty, including those who might be resistant to change, so that a common vision of effective mathematics teaching can positively impact instruction system-wide. To aid in this effort, identifying the specific aspects that faculty participants value is important as networks, like the COMMIT Network, gain momentum, expand, and become sustainable. Findings from this study, conducted during the COVID-19 global pandemic, provide preliminary ideas on how similar networks can function to collectively support CoPs with ongoing rather than finite goals.

Faculty participants in our study engaged in a variety of ways within their COMMITs. Not only were they spread throughout different regions across the USA, but their COMMIT engagement varied in type and duration based on their own preferences or availability. For example, while many events were originally held in-person, COVID-19 conditions required swift shifts to online collaborations. Further, while 
some participants engaged in one-time workshops, others collaborated in ongoing activities such as book club conversations around teaching with inquiry. Even through challenging times, participating mathematics faculty continued to engage in their COMMITs and the three overarching themes of participant value all related to how they felt supported.

Faculty members valued the immediate resources and ideas they learned from expert and novice peers they connected with through their regional COMMIT. Mathematics faculty often have minimal ongoing pedagogical training (Banta, 2003). With access to learning about the Four Pillars and other foundations of teaching with inquiry environments within their COMMITs, faculty can reflect, modify, and adjust their teaching in big or small ways to navigate their local environment and context. COVID-19 conditions only heightened the need for resources and support beyond the departmental level with most faculty scrambling for solutions at home, especially related to technology and assessment. COMMITs, like other CoPs, provide a place for faculty participants to connect, brainstorm and share resources, and problem solve through new instructional challenges (Furco \& Moely, 2012).

Our findings point to the value of COMMITs in their ability to bring faculty together to focus on teaching and assessment practices which might not otherwise be a focus of their professional development. When shifting away from traditional lecture-style methods of instruction, the COMMITs provided near-peers to support each other through theoretical and pedagogical shifts in mathematics instructional practice (Jaworski \& Gellert, 2011). Participant value was not only the immediate support and connections they experienced, but also the potential and realized value of how these new ideas and networking might impact their future work. Faculty face the pressures of student evaluations, enrollment, and other potential research and service responsibilities of their position. Engaging with other faculty members who share interest and investment in instructional excellence can be empowering and limit faculty feeling like they are alone on an island to figure out how to support student learning and increase student success in mathematics (Fayer et al., 2017). Providing a consistent space for faculty to support ongoing change in their own practice through community building can also make it possible for them to become change agents by recruiting and supporting additional STEM faculty engaging in these reform efforts.

It is difficult/impossible to offer national professional development for all faculty. Grassroots, localized CoP models, such as COMMITs in this study, offer a flexible alternative that has the potential to be sustainable and to easily support more faculty as numbers increase. Our findings show that many faculty members are still being introduced to "IBL Basics" and foundational concepts of active learning classrooms. COMMITs have the ability to scaffold programming for the various levels of experience and comfort with teaching with inquiry in ways departments may not be able to provide. Our participants valued that COMMIT activities were a place where they could be vulnerable. The regional aspect promotes a safe environment for faculty members to be vulnerable in sharing their level of experience or knowledge about inquiry with others. Because the programming is run by faculty in the field, the professional development opportunities have the potential to meet the needs of faculty in the region efficiently and effectively. The CoPs also provides a model where 
faculty are supporting faculty. This can help to maintain stability of the network over time where expertise is not viewed as an external source held by few, but an internal model led by many.

Underpinning the findings of our study is the ability to identify cross-cutting themes throughout the regional COMMITs that might inform the larger network. Kezar and Gehrke (2017) point to the role of networks in establishing sustainable systems of change. The cyclical nature of CoPs and network interactions align with Bernstein-Sierra and Kezar's (2017) call for more goal-based policies, structures, and leadership plans to ensure the localized CoPs are sustainable. A clearer understanding of what participants find valuable in their professional development at the local level can inform the network's ability to support its CoPs. While the CoPs may act independently, the larger network acts as a bridge to connect faculty to peers and resources with a common vision as a way to avoid "reinventing the wheel" or working in isolation. This allows the network to be more responsive and able to refine structural supports that promote the ongoing growth and sustainability of the CoPs it supports.

Interrogating what individuals within a $\mathrm{CoP}$ network value and further, identifying what value CoPs can collectively have on individuals and systems, is a complex task. By using the value-creation framework, we are able to gain further understanding about how CoPs communicate, collaborate, and share knowledge (Guldberg et al., 2021; Kezar \& Gehrke, 2015; Roux et al., 2006). It can also enrich understanding of how participatory research can lead to knowledge co-creation and in turn impact on practice. Alongside research on active learning and teaching with inquiry is always the conversation of professional development at both local and national levels. Our findings support the research of Apkarian et al. (2021) showing that instructors with different individual characteristics and representing different contexts and institutions are able to incorporate active learning into their instruction. With local and national support mechanisms in place and colleagues nearby, it is more likely faculty will implement teaching with inquiry when they are not alone in the mission.

Faced with the challenges of a global pandemic and swift changes to instructional environments, our findings show that COMMITs were able to respond to and support faculty in ways they found valuable to promote the ongoing use of teaching with inquiry. We anticipate various implications for these findings and also offer a call for future research investigating how the value of faculty participation can be supported by an overall network structure that can collectively unite local CoPs. First, we are eager to build upon other research to see how faculty participants apply what they learn and how they leverage their COMMIT Network connections to implement and sustain teaching with inquiry practices. Further examination of how immediate and potential value might translate or expand to applied, realized and/or transformative value, and in what particular areas, are exciting future directions for this work, particularly in the areas of diversity, equity, and inclusion. As programming and recruitment of faculty who represent diverse perspectives continue to grow within COMMITs and the network, we seek to examine how faculty value translates to providing more equitable access and student learning outcomes in the classroom. 
COMMITs are interested in not only the increased adoption of teaching with inquiry practices in college mathematics, but the long-term sustainability and transformation of the field of mathematics teaching. To foster such long-term change, it is critically important to understand what types of support are needed to meet such goals. Studying the potential of CoP networks, particularly ones supporting nonorganizational CoPs, as a way to facilitate structures and resources to aid this effort, is currently an under researched topic in the literature. This study provides some insights into the types of activities that faculty find valuable as an indirect indicator of what the broader network can do to help, but additional research is needed to examine the actual role of the network in providing such scaffolding. It is our hope that other, similar projects seeking to connect regional CoPs can learn from our current research and continue the effort to better understand the potential of these bridges to support sustainable CoPs.

Supplementary Information The online version contains supplementary material available at https://doi. org/10.1007/s41979-021-00061-3.

Acknowledgements We thank the COMMIT Network and regional COMMIT leaders for their tireless work. We also thank COMMIT faculty participants for their collaboration. We acknowledge the work presented in this paper was supported by National Science Foundation Grant No. \#1925188. Any opinions expressed herein are those of the authors and do not necessarily reflect the views of the foundation.

\section{References}

Apkarian, N., Henderson, C., Stains, M., Raker, J., Johnson, E., \& Dancy, M. (2021). What really impacts the use of active learning in undergraduate STEM education? Results from a national survey of chemistry, mathematics, and physics instructors. PLOS ONE, 16(2), e0247544. https://doi.org/10. 1371/journal.pone.0247544.

Austin, A. E. (2011). Promoting evidence-based change in undergraduate science education. National Academies National Research Council Board on Science Education. https://sites.nationalacademies. org/cs/groups/dbassesite/documents/webpage/dbasse_072578.pdf. Accessed 5 Oct 2021.

Banta, T. W. (2003). Quality and accountability in higher education: Improving policy, enhancing performance. Journal of Higher Education, 76(1), 112-114. https://doi.org/10.1080/00221546.2005. 11772279.

Bernstein-Sierra, S., \& Kezar, A. (2017). Identifying and overcoming challenges in STEM reform: A study of four national STEM reform communities of practice. Innovative Higher Education, 42(5), 407-420. https://doi.org/10.1007/s10755-017-9395-X.

Boothe, S., \& Kellogg, S. (2015). Value creation in online communities for educators. British Journal of Educational Technology, 46(4), 684-698. https://doi.org/10.1111/bjet.12168.

Bowen, C. W. (2000). A quantitative literature review of cooperative learning effects on high school and college chemistry achievement. Journal of Chemical Education, 77(1), 116-119. https://doi.org/10.1021/ed077p116.

Bradley, E. H., Curry, L. A., \& Devers, K. J. (2007). Qualitative data analysis for health services research: Developing taxonomy, themes, and theory. Health Services Research, 42(4), 1758-1772. https://doi. org/10.1111/j.1475-6773.2006.00684.x.

Campbell, R., Clark, D. \& O'Shaughnessy, J. (Eds.) (2020). Introduction to the special issue on implementing mastery grading in the undergraduate mathematics classroom [Special issue]. PRIMUS, 30(8-10), 837-848. https://doi.org/10.1080/10511970.2020.1778824.

Clarke, L., Galvin, C., Campbell, M., Cowan, P., Hall, K., Magennis, G., O’Doherty, T., Purdy, N., \& Abbott, L. (2021). Oxford Review of Education, 47(1), 79-97. https://doi.org/10.1080/03054985.2020.1835624. 
Cook-Sather, A., Abbot, S., \& Silvers, H. (2016). Translating partnerships: How faculty-student collaboration in explorations of teaching and learning can transform perceptions, terms, and selves. Teaching \& Learning Inquiry, 4(2), 1-14. https://doi.org/10.20343/teachlearninqu.4.2.5.

Daly, A. J. (2010). Mapping the terrain: Social network theory and educational change. In A. J. Daly (Ed.), Social network theory and educational change (pp. 1-17). Harvard Education Press.

De Vlieger, P., Jacob, B., \& Stange, K. (2016). Measuring up instructor effectiveness in higher education. https://doi.org/10.3386/w22998.

Engel, P., \& van Zee, A. (2004). Networking for learning: What can participants do? European Centre for Development Policy Management.

Fayer, S., Lacey, A., \& Watson, A. (2017). STEM occupations: Past, present, and future. U.S. Bureau of Labor Statistics. https://www.bls.gov/spotlight/2017/science-technology-engineering-and-mathematicsstem-occupations-past-present-and-future/pdf/science-technology-engineering-and-mathematics-stemoccupations-past-present-and-future.pdf. Accessed 5 Oct 2021.

Freeman, S., Eddy, S. L., McDonough, M., Smith, M. K., Okoroafor, N., Jordt, H., \& Wenderoth, M. P. (2014). Active learning increases student performance in science, engineering, and mathematics. Proceedings of the National Academy of Sciences, 111(23), 8410-8415. https://doi.org/10.1073/pnas. 1319030111.

Furco, A., \& Moely, B. E. (2012). Using learning communities to build faculty support for pedagogical innovation: A multi-campus study. The Journal of Higher Education, 83, 1-28. https://doi.org/10.1080/ 00221546.2012 .11777237$.

Guldberg, K., Achtypi, A., D’Alonzo, L., Laskaridou, K., Milton, D., Molteni, P., \& Wood, R. (2021). Using the value creation framework to capture knowledge co-creation and pathways to impact in a transnational community of practice in autism education. International Journal of Research \& Method in Education, 44(1), 96-111. https://doi.org/10.1080/1743727x.2019.1706466.

Haak, D., HilleRisLambers, J., Pitre, E., \& Freeman, S. (2011). Increased structure and active learning reduce the achievement gap in introductory biology. Science, 332, 1213-1216. https://doi.org/10.1126/ science. 1204820

Healey, M., Flint, A., \& Harrington, K. (2014). Engagement through partnership: Students as partners in learning and teaching in higher education. HE Academy. https://www.heacademy.ac.uk/engagementthrough-partnership-students-partners-learning-and-teachinghigher-education. Accessed 5 Oct 2021.

Healey, M., Flint, A., \& Harrington, K. (2016). Students as partners: Reflections on a conceptual model. Teaching \& Learning Inquiry, 4(2), 8-20.

Henri, F., \& Pudelko, B. (2003). Understanding and analysing activity and learning in virtual communities. Journal of Computer Assisted Learning, 19(4), 472-487. https://doi.org/10.1046/j.0266-4909.2003.00051.x

Hrabowski, F., \& Henderson, P. (2017). Toward a more diverse research community models of success: A forward-looking group of colleges and universities are demonstrating effective ways to educate underrepresented minorities for careers in science and engineering. Issues in Science \& Technology, 33(3), 33-40.

Jaworski, B., \& Gellert, U. (2011). Educating new mathematics teachers: Integrating theory and practice, and the roles of practicing teachers. In A.J. Bishop, M.A. Clements, C. Keitel, J. Kilpatrick, \& F. K. S. Leung (Eds.), Second international handbook of mathematics education (pp. 829-875).

Kezar, A. (2013). How colleges change. Routledge.

Kezar, A. \& Gehrke, S. (2015). Communities of transformation and their work scaling STEM reform. Pullias Center for Higher Education Rossier School of Education University of Southern California. https://pullias.usc.edu/ download/communities-of-transformation-and-their-work-scaling-stem-reform/. Accessed 5 Oct 2021.

Kezar, A., \& Gehrke, S. (2017). Sustaining communities of practice focused on STEM reform. The Journal of Higher Education, 88(3), 323-349. https://doi.org/10.1080/00221546.2016.1271694.

Keza, A., Gehrke, S., \& Bernstein-Sierra, S. (2018). Communities of transformation: Creating changes to deeply entrenched issues. The Journal of Higher Education, 89(6), 832-864.

Krippendorff, K. (2004). Content analysis: An introduction to its methodology (2nd Ed.). Sage.

Laursen, S., \& Rasmussen, C. (2019). I on the prize: Inquiry approaches in undergraduate mathematics. International Journal of Research in Undergraduate Mathematics Education, 5(1), 129-146. https:// doi.org/10.1007/s40753-019-00085-6.

Laursen, S. L., Hassi, M.-L., Kogan, M., \& Weston, T. J. (2014). Benefits for women and men of inquirybased learning in college mathematics: A multi-institution study. Journal for Research in Mathematics Education, 45(4), 405-418. https://doi.org/10.5951/jresematheduc.45.4.0406.

Laursen, S., Andrews, T., Stains, M., Finelli, C. J., Borrego, M., McConnell, D., Johnson, E., Foote, K., Ruedi, B., \& Malcom, S. (2019). Levers for change: An assessment of progress on changing STEM instruction. American Association for the Advancement of Science. 
Lave, J., \& Wenger, E. (1991). Situated learning: Legitimate peripheral participation. Learning in doing. Cambridge University Press.

Lord, S., Berger, E. J., Kellam, N. N., Ingram, E. L., Riley, D. M., Rover, D. T., Salzman, N., \& Sweeney, J. D. (2017). Talking about a revolution: Overview of NSF RED projects [Paper presentation]. American Society for Engineering Education (ASEE) annual conference and exposition.

Lueddeke, G. R. (1999). Toward a constructivist framework for guiding change and innovation in higher education. The Journal of Higher Education, 70, 235-260.

Malcom, S., \& Feder, M. (Eds.) (2016). Barriers and opportunities for 2-year and 4-year STEM degrees: Systemic change to support students' diverse pathways. National Academy of Engineering; National Academy of Sciences, Engineering, and Medicine. https://www.nap.edu/catalog/21739/barriers-andopportunities-for-2-year-and-4-year-stem-degrees. Accessed 5 Oct 2021.

Merriam, S. (2009). Qualitative research: A guide to design and implementation. Wiley.

Miles, M., Huberman, A., \& Saldaña, J. (2014). Qualitative data analysis: A methods sourcebook (3rd ed.). Sage.

Nolan, K. (2006). A socio-cultural approach to understanding pre-service teachers' negotiated journeys through theory/practice transitions [Paper presentation]. Annual meeting of the American Educational Research Association (AERA).

Nolan, K. (2010). Playing the field(s) of mathematics education: A teacher educator's journey into pedagogical and paradoxical possibilities. In M. Walshaw (Ed.), Unpacking pedagogy: New perspectives for mathematics classrooms (pp. 153-173). Information Age.

Rasmussen, C., Aprkarian, N., Hagman, J. E., Johnson, E., Larsen, S., \& Bressoud, D. (2019). Characteristics of precalculus through calculus 2 programs: Insights from a national census survey. Journal for Research in Mathematics Education, 50(1), 98-112. https://doi.org/10.5951/jresematheduc.50.1.0098.

Rose, H., \& Betts, J. R. (2001). Math matters: The links between high school curriculum, college graduation, and earnings. Public Policy Institute of California.

Roux, D. J., Rogers, K. H., Biggs, H. C., Ashton, P. J., \& Sergeant, A. (2006). Bridging the science-management divide: Moving from unidirectional knowledge transfer to knowledge interfacing and sharing. Energy and Society, 11, 4-23. https://doi.org/10.5751/ES-01643-110104.

Saldaña, J. (2015). The coding manual for qualitative researchers (3rd ed.). Sage.

Smith SU, Hayes S, \& Shea P (2017) A critical review of the use of Wenger's community of practice (CoP) theoretical framework in online and blended learning research, 2000-2014. Online Learning 21(1):209237. https://doi.org/10.24059/olj.v21i1.963.

Theobald, E. J., Hill, M. J., Tran, E., Agrawal, S., Arroyo, E. N., Behling, S., Chambwe, N., Laboy Cintron, D., Cooper, J. D., Dunster, G., Grummer, J. A., Hennessey, K., Hsiao, J., Iranon, N., Jones II, L., Jordt, H., Keller, M., Lacey, M. E., Littlefield, C. E., Lowe, A., Newman, S., Okolo, V.., Olroyd, S., Peecook, B. R., Pickett, S. B., Slager, D. L., Caviedes-Solis, I. W., Stanchak, K. E., Sundaravardan, V., Valdebenito, C., Williams, C.R., Zinsli, K., \& Freeman, S. (2020). Active learning narrows achievement gaps for underrepresented students in undergraduate science, technology, engineering, and math. Proceedings of the National Academy of Sciences.

Tomkin, J. H., Beilstein, S. O., Morphew, J. W., \& Herman, G. L. (2019). Evidence that communities of practice are associated with active learning in large STEM lectures. International Journal of STEM Education, 6(1), 1-15. https://doi.org/10.1186/s40594-018-0154-z.

Valente, T. (1995). Network models of the diffusion of innovations. Hampton Press.

Wenger, E. (1998). Communities of practice: Learning, meaning, and identity. Cambridge University Press.

Wenger, E., Trayner, B., \& de Laat, M. (2011). Promoting and assessing value creation in communities and networks: A conceptual framework. Open University of the Netherlands.

Wenger-Trayner, E., \& Wenger-Trayner, B. (2014). Learning in a landscape of practice: A framework. In E. Wenger-Trayner, M. Fenton-O'Creevy, S. Hutchinson, C. Kubiak, \& B. Wenger-Trayner (Eds.), Learning in landscapes of practice: Boundaries, identity, and knowledgeability in practice-based learning (pp. 13-29). Routledge.

Wenger-Trayner, E., \& Wenger-Trayner, B. (2015). Introduction to communities of practice. https://wengertrayner.com/introduction-to-communities-of-practice/. Accessed 5 Oct 2021.

Werder, C., \& Otis, M. (2010). Engaging student voices in the study of teaching and learning. Stylus.

Publisher's Note Springer Nature remains neutral with regard to jurisdictional claims in published maps and institutional affiliations. 